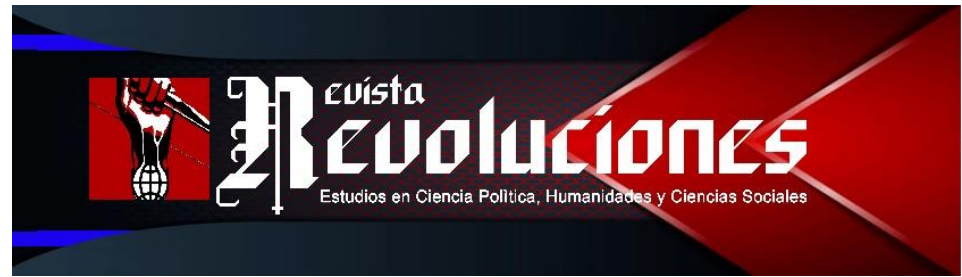

\title{
DESDE LAS VOCES SILENCIADAS EN EL SURANDINO, RESURGEN NUEVAS LÍNEAS DE PENSAMIENTO EMANCIPATORIO
}

\author{
From the silenced voices in the Surandino, new lines of emancipatory thought \\ resurface
}

\author{
Vicente Alanoca Arocutipa ${ }^{1}$ \\ UNIVERSIDAD NACIONAL DEL ALTIPLANO \\ PUNO \\ valanoca@unap.edu.pe \\ https://orcid.org/oooo-0001-9111- \\ 0704
}

\author{
DOI: https://doi.org/10.35622/j.rr.2019.01.003 \\ Recibido: 07-I-2019 / Aceptado: 29-I-2019 / Actualizado: 15-VII-2020
}

\section{Resumen}

Estamos asistiendo a tiempos más complejos de crisis, porque hoy nos tienen confinados con el virus o bajo su nombre estamos encerrados, invisibilizados, amenazados y susceptibles de contagio. El objetivo es contextualizar las líneas de pensamiento y acción de sus impulsores. En la metodología se ha rastreado diversas publicaciones y producciones en esta perspectiva. Los resultados, nos evidencian que Revoluciones es una publicación que surge y nace desde esas voces silenciadas y relegadas, un colectivo decido a acoger líneas y acciones de pensamiento emancipatorio. Dará mucho que hablar, debatir, sobre todo encarar y encarnar sobre las formas de hacer ciencia política, humanidades y sociales. Es complejo empezar, abrir los velos de la exclusión y entrar a la palestra del debate, pero en el marco de respeto y la humildad sin violencia ni apasionamientos. Una verdadera arma de la revolución en los tiempos actuales es la educación, y ello implicar ser revolucionario de verdad en nuestras formas de pensar, hacer, saber, actuar, querer y actuar por la dignidad humana, en este caso por la dignidad de nuestros pueblos de todas las sangres.

Palabras Clave: Crítica, emancipación, lucha, pensamiento, otras voces.

\begin{abstract}
We are attending more complex times of crisis, because today we are confined to the virus or under its name we are locked, invisibilized, threatened and susceptible to contagion. The objective is to contextualize the lines of thought and action of its promoters. Various

\footnotetext{
1 Aymara, antropólogo, Docente de la Escuela Profesional de Antropología, Facultad de Ciencias Sociales, Universidad Nacional del Altiplano (UNA), Perú. Doctor por la Universidad Pablo Olavide, Sevilla (España).
} 
publications and productions have been tracked in the methodology in this perspective. The results show us that Revolución is a publication that arises and is born from those silenced and relegated voices, a collective that decides to accept lines and actions of emancipatory thought. It will give much to talk, debate, especially face and embody on the ways of doing political, humanities and social science. It is complex to start, open the veils of exclusion and enter the arena of debate, but within the framework of respect and humility without violence or passion. A true weapon of the revolution in the current times is education, and this implies being truly revolutionary in our ways of thinking, doing, knowing, acting, loving and acting for human dignity, in this case for the dignity of our peoples of all bloods.

Keyword: Criticism, emancipation, struggle, thought, other voices.

\section{INTRODUCCIÓN}

Siempre es un honor poner sobre la mesa algunas líneas aunque nos cueste, hoy para quienes procedemos de las cenizas y llantos de los pueblos denegados sistemáticamente e históricamente (Bonfil, 2001), que sobre ellas se han fundado estados o comunidades imaginadas (Anderson, 1997), a pesar de que se admita la ciudadanía multicultural (Kymlicka, 1996), sobre ella hemos abordado en estos últimos años desde diversos espacios académicos y sociales. Pero, por el eurocentrismo solapado (Martin-Barebero, 1987), el cual se reproduce en el los espacios de la academia local, que el rezago blindaba y hoy blinda desde diferentes espacios se menosprecia estos modestos aportes y apuestas.

El presente son líneas o pinceladas que elaboramos en momentos difíciles y complejos que nos tocó vivir a todos los que nos cogió la crisis mundial de la pandemia, el cual ha desnudado por completo a nuestras instituciones del Estado de la desgracia que siempre han estado, en el caso peruano por más 200 años. Hoy somos testigos del contagio incontrolable y muerte de personas, al cual estamos propenso todos, ni la academia, ni el personal de salud, peor aún la sociedad puede encontrar algún vicio de control, se han ido al carajo, los rankings y estándares de control de las mejores universidades en el caso nacional e internacional están lejos de cumplir su responsabilidad social, a ello sumado la ausencia de liderazgo de las autoridades nacionales y locales, muchos de ellos aprovecharon para beneficiarse con las utilidades a cualquier costo, mientras a la población nos obligaron a "quedarse en casa" atemorizado, con "autodetención domiciliaria", lo cierto es que estamos viviendo una situación incierta, no sabemos que va pasar mañana, al parecer se acerca más y más la muerte.

La revista Revoluciones, estudios en Ciencia Política, Humanidades y Sociales, desde nuestro punto de vista, son esas voces que surgen desde el Surandino como nuevas voces y líneas de pensamiento emancipatorio, con sus matices y perfiles propios, a iniciativa de una juventud no sólo inquieta, sedienta y comprometida, sino inteligente, con sapiencia y con acción emancipatoria, como diría Antonio Gramsci: "decir la verdad es siempre revolucionario", por ello, pienso y siento como un doliente de la cultura y la lengua aymara, como otros militantes convictos a quitar esos velos, acción de sus propios actores, no de intermediarios, ni de voceros, sino desde los "propios condenados de los pueblos del 
Surandino" parafraseando a Fanon. Son quienes, que no se han lavado con aguas de la colonia, sino que siempre predispuestos al debate alturado y respetuoso para encarar la mediocridad y la falacia de la academia excluyente y racista. En lo personal y profesional, esta tribuna y sus secciones serán plataformas de aliento para seguir bregando en este trajinar tan complejo, racista, discriminatoria, corrupta y elitista, como hijos y herederos de los quechuas, aymaras, uros y amazónicos, respetando las otras voces mestizas que se unen desde otras partes del país y del mundo desde su compromiso y desde sus particularidades.

\section{METODOLOGÍA}

El trabajo es de tipo revisión, se ha rastreado información argumentativa sobres las reflexiones y debates que se han ido desarrollando en estos últimos años desde el Surandino, a partir de ello se aborda dos ítems que nos parecen que encarnan, o por lo menos son las que la revista debería enrumbarse si es que pretende contribuir desde sus diferentes, números, secciones y acciones, que son las que hace falta en la región.

\section{RESULTADOS Y DISCUSIÓN}

Por una cuestión metodológica abordamos desde dos ítems, en el primero nos referimos al pensamiento crítico, el cual hemos trabajado en diferentes revistas, libros y notas como: el desarrollo del pensamiento crítico en el altiplano de Puno, (Alanoca, 2016) y la universidad en el proceso de la reconstrucción del pensamiento crítico (Alanoca, 2017), entre otros como en las presentaciones y ponencias que realizamos en Puebla (México), Iquique (Chile), Salamanca (España), etc., donde desde las preguntas, las críticas y aportes han ido consolidándose nuestra propuesta, desde la lucha constante y cotidiana, pisando tierra desde los ideales de nuestros ancestros. No son una guía y lo mejor, sino son los charcos donde nos movemos y siempre predispuestos a dialogar sin disfraces ni máscaras, por la dignidad de los pueblos desde ese espacio que nos toca asumir.

\section{El pensamiento crítico como ingredientes de las voces silenciadas}

No podemos ser ingenuos a voces y acciones emergentes frente a la dominación, instaurada desde el sistema educativo, o círculos de poder que han y siguen controlando muchos espacios académicos bajo el nombre de los "estándares de calidad", y sobre el lastre de "maestritis y doctoritis" a nombre de Dios, mercado, ahora bajo el virus o de la pandemia, que se han convertido a ser invisibles, como fue los tres unicornios que han sido el capitalismo, el colonialismo y el patriarcado. Estos son los principales modos de dominación. Para dominar efectivamente, tienen que ser imprudentes, feroces e incapaces de ser dominados, como advierte Da Vinci (Santos, 2020).

Desde el sistema educativo se han disfrazado y maquillado bajo la categoría de la "interculturalidad", "inclusión", "transparencia", "calidad" y se pusieron "poncho", "chuspa" y "chaleco" de aymaras, quechuas, uros y amazónicos, de colores del arco iris, que en la práctica en sus mentes y sus corazones son rojetes, vividores, manchadas de sangre, 
encubriendo con su viveza criolla hechos de corrupción e injustica, creyendo que tiene la capacidad moral y ética como para "enseñar" a los "indios", "salvajes", "revoltosos" y "conflictivos", les decimos, que se equivocaron, que deben admitir y aceptar que existen los "otros" de quienes en su nombre hablan, se visten y disfrutan, o "bajo su máscara de generoso y futurismo, el progresista no se preocupa del futuro" (Ortega y Gasset, 1975, pág. 76). Esa frase de Tupak Katari: "nayaruwa jiwatapxitata, naxarusti waranqa waranqanakawa kutanipxani" se hace más evidente, el que supo encarar y encarnar Churata en el Altiplano a partir del grupo Puno Orkapata, el cual nos falta deshilvanar desde la perspectiva antropológica, sociológica, filosófica y desde la cotidianidad, porque sólo nos hemos reducido, en este caso desde la perspectiva estrictamente de la literatura (Alanoca, 2019), esto nos debe conllevar a interactuar interdisciplinariamente y de manera colectiva ligada a nuestros quehaceres de la lucha cotidiana de nuestros pueblos.

En fin, todos los hombres, al margen de su profesión, manifiestan alguna actividad intelectual, y ya sea como filósofo, artista u hombre de gusto, participa de una concepción del mundo, observa una consecuente línea de conducta moral y, por consiguiente, contribuye a mantener o a modificar un concepto universal, a suscitar nuevas ideas (Gramsci, 1967, pág. 26).

En el Surandino se han silenciado las sabidurías cotidianas de los hombres y mujeres de manera sistemática desde dos escenarios muy definidos como fue la escuela y la iglesia, sobre ellas existen trabajos interesantes y serios, como es la religión (Silleta, 2007), o la lucha por la educación como el caso Warisata (Bolivia), Utawilaya (Alanoca, Condori, \& Mamani, 2019), a pesar de que el protestantismo en su momento con el caso de la Iglesia Adventista ha contribuido en la lucha por la educación rural. Esto como en la primera etapa de la lucha por la educación para los pueblos de la periferia. Un segundo momento es la fundación o creación de los núcleos escolares campesinos, a partir de ello se va generar la educación intercultural bilingüe desde el año 1975 hasta 1990, desde donde se va enfatizar en la lengua y la cultura, desde la academia, pero en la perspectiva culturalista contemplativa, bajo la bandera del interculturalismo, el cual ha absorbido y apagado las acciones críticas, bajo el nombre de la educación formal. Si bien es cierto que existe una nueva reconfiguración de actores y sujetos emancipatorios desde los pueblos de la periferia (Alanoca, 2017), que vendría ser un tercer momento, donde existe un resurgir de reflexiones, sobre todo impulsada desde las organizaciones sociales y desde sus diversos espacios de lucha, donde va enfatizar en la importancia de la lengua y la cultura, desde el mismo Estado, y de los propios actores, aunque con contenidos sarcásticos y estigmatizantes desde los diversos sectores de la gestión pública.

\section{Voces y acciones de líneas de pensamiento emancipatorio}

Uno de los espacios que ha legitimado y regulado un tipo de conocimiento es la academia, relegando las otras formas de conocimiento (Santos, 2010), bajo los cánones del sistema universitario, donde se ha relegado sobre todo a las ciencias sociales, concretamente las investigaciones, ello ya había sido advertido ya por la misma UNESCO (2016) donde vierte sobre las principales desigualdades que son parte y agenda de las universidades en sus 
investigaciones, cuyas consecuencias serían nefasta para los pueblos del mundo y de América Latina. Esta situación hoy es muy preocupante:

Sin duda el contexto actual plantea un panorama preocupante para el proyecto de época que constituyen las ciencias sociales en nuestra región, en tanto, como plantean los autores del texto, las políticas de Estado signadas por ajustes brutales en la ciencia y la educación a través de recortes presupuestales, apuntan claramente al desmantelamiento tanto del sistema científico y tecnológico, como del sistema educativo público. Es relevante el análisis expuesto en la obra en torno a que el cataclismo del sistema educativo en general y las universidades en particular no es solo una cuestión de índole económica, sino que configura un fenómeno de época que trae consigo profundos cambios y retos socioculturales a los que el sistema educativo e investigativo debe hacerles frente.

En muchos países como el caso de Bolivia, donde fue sacado bajo un golpe de Estado el líder aymara Evo Morales, el encarcelamiento a Lula en Brasil, la persecución a líderes sociales, el racismo y exclusión y discriminación en los espacio de la academia, donde a y en nombre de la academia nunca tomaron en cuenta las propuestas y las iniciativas de gente de procedencia de la periferia, donde sus aportes y reflexiones tienen elementos y contenidos propios, no contaminados, auténticos, sobre todo pertinentes y contextuales bajo el liderazgo de egresados y profesionales de las universidades del Surandino. En el Perú, caso concreto en Puno, estábamos asistiendo antes de la declaratoria de la emergencia nacional por el caso de la pandemia de la Covid-19 al cierre de dos universidades asentadas en la región, pero es necesario conocer la situación de las universidades, cómo es su situación actual, el cual es una asignatura pendiente, a pesar de todas las críticas y sobre todo las dos universidades por la denegación a su licenciamiento, se quita el derecho a una educación universitaria a la juventud quechua, aymara y mestizo que estudiaba en estos centros de universidades.

Tabla 1. Situación de las universidades de Puno según SUNEDU al 2020

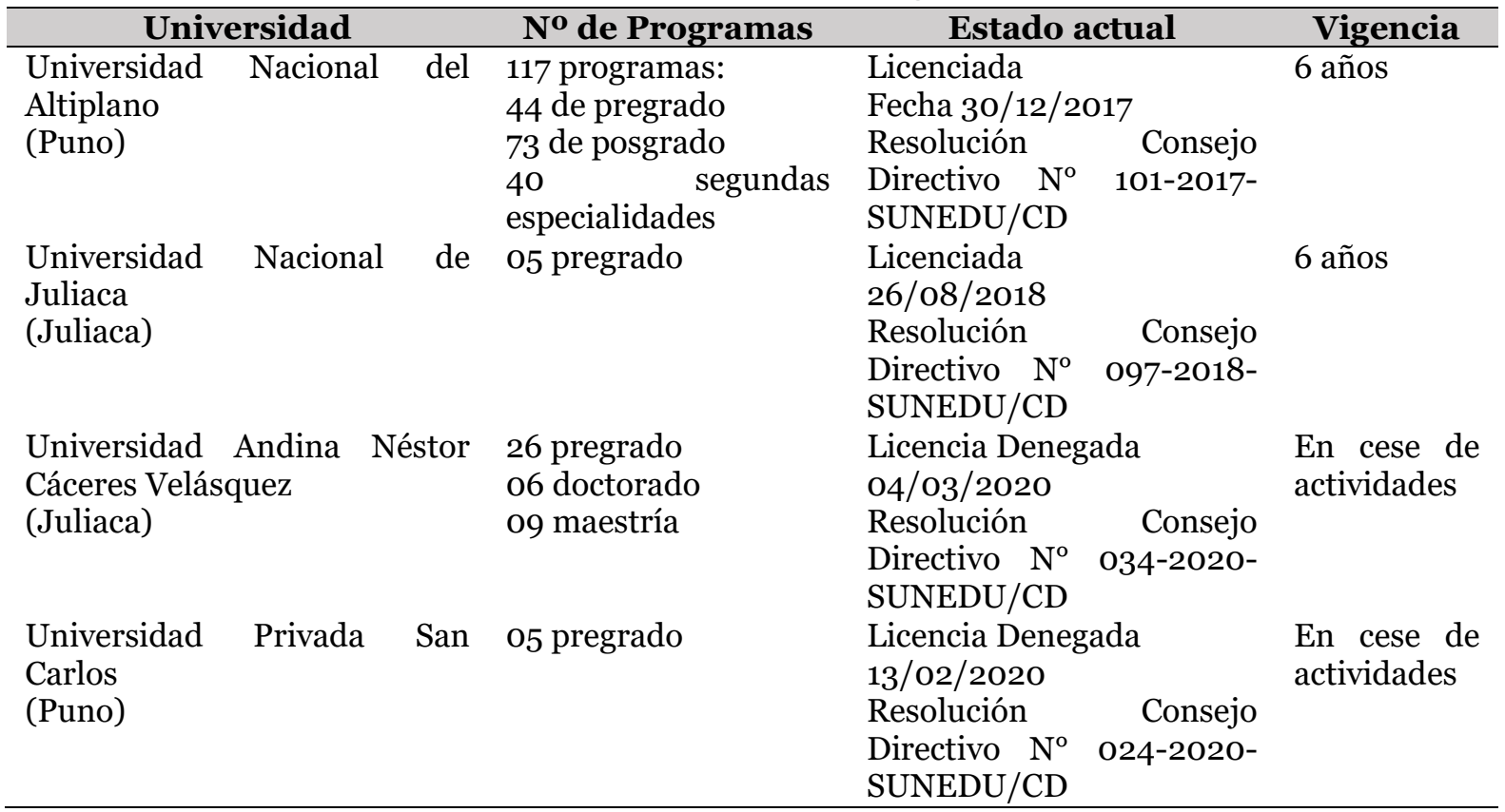

Fuente: Elaborado según los datos de SUNEDU y portal web de las universidades 2020. 
En la región Puno están asentadas cuatro universidades de las cuales dos son públicas y dos son privadas; la Universidad Nacional del Altiplano ha sido el primero en lograr el licenciamiento; luego la Universidad Nacional de Juliaca; aunque la Universidad Andina Néstor Cáceres Velásquez asentada en Juliaca aún no había logrado su licenciamiento, pero el 04 marzo del 2020 fue denegada su licenciamiento. Como se percibe y por la experiencia que tenemos de haber sido parte del proceso de licenciamiento de la UNA-Puno, no era tan complejo. En el caso de la Universidad Privada de San Carlos, fue denegado su licenciamiento el 13 de febrero del 2020. Más allá de los cuestionamientos a la calidad, lo cierto es que se deja sin esperanza a una educación universitaria a toda una juventud, pero con lo de la pandemia se deja "encerrado en su casa" mucho más aun grave, por las suspensiones de los exámenes de admisión a otras universidades, sumado a la falta de recursos, para buscar otras posibilidades en universidades nacionales y extranjeras.

Esta situación es una respuesta desde el sistema universitario en el Perú a los que se vienen imponiéndose desde afuera las recetas y procesos de homogenización y estandarización, porque:

El capital simbólico, cultural, social o económico se convierte en moneda de cambio para lograr mejores posicionamientos en el campo y el cumplimiento de los fines que demanda la organización. En la medida que los científicos logran obtener o desarrollar alguno de estos capitales, tienen mejores condiciones para posicionarse en el campo, lo que fortalece su convicción de continuar desarrollando estos capitales. Esta racionalidad económica se vincula directamente con la lógica de mercado que prevalece en nuestras sociedades modernas y que las universidades han venido asumiendo poco a poco (Pérez , 2020).

En cuanto a la producción intelectual, que es el propósito de la presente, es necesario precisar las diferentes producciones que cuentan las universidades es casi irrelevante en torno a la perspectiva crítica y de pertenencia, se menosprecia y se asedia las ciencias sociales, sino que siempre siguen recetas y modelos excluyentes.

Por consiguiente, nos obliga a la urgencia por decir "nosotros" (Portocarrero G. , 2015 ), en nuestro caso desde las ciencias sociales, aunque la tarea de ordenar, sistematizar y analizar la información sobre la desigualdad no es una tarea fácil (Alarco, 2019), muchos autores y estudiosos de renombre reconocen y admiten la complejidad, en realidad estudiar el Perú implica caminar sobre una compleja y movediza trama hecha de filamento s viejos y otros recientes que se entretejen para dar lugar a lo nuevo y lo inédito (Portocarrero \& Vergara, 2019), es cual se reproduce en otros espacios como Puno, por ejemplo sigue vigente ese racismo del rezago colonial, o el gamonalismo que finge de aliado y muchas veces pretende liderar en algunos espacios de la academia como son las universidades. Tiene que desanclarse de los modelos de estandarización y homogenización que han caído hasta ahora, ello significa no desconocer la ciencia, sino recrearla desde el contexto del dolor y saber.

Tabla 2: Número de Revistas por Universidad en Puno al año 2020

\begin{tabular}{c|cc}
\hline Universidad & Título de la Revista & $\begin{array}{c}\mathbf{N}^{\circ} \text { de } \\
\text { Revistas }\end{array}$ \\
\hline
\end{tabular}

Revista Revoluciones -19- Vol. 1, No 1 (2019), pp. 14-24

Esta obra está bajo una licencia internacional Creative Commons Atribución 4.o. 


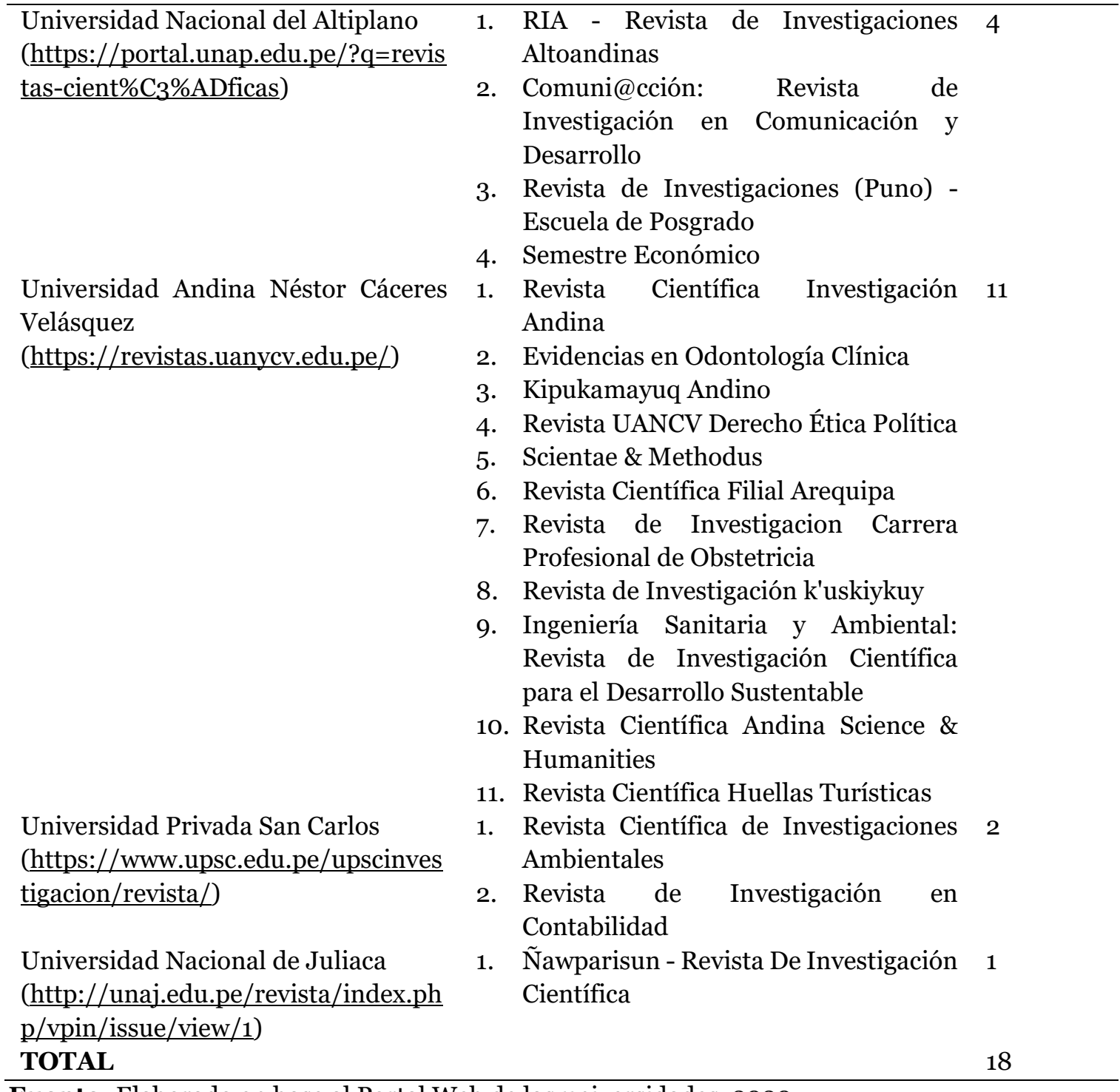

Fuente: Elaborado en base al Portal Web de las universidades, 2020

De la Tabla 2 se desprende que existen 18 publicaciones, la UANCV ha generado 11 revistas, aunque éstas no han mantenido la periodicidad, pero ya es un avance; mientras la UNA-Puno cuenta con 04 revistas, dos de ellas con un gran avance en el proceso de indización, porque ya está en Scielo; la UNAJ con 02 revistas y la UPSC con sólo una revista. Son aportes interesantes, son cambios que se venían generando desde adentro, expresiones de estrategias de diálogo entre los actores de cada universidad. Sabemos que no se trata de tener más revistas, aunque es bueno, pero lo importante es la relevancia, para ello necesitamos aterrizar en diálogos de las temáticas del contexto:

The Peruvian State has designed some dialogue strategies in recent years, within the framework of the national agreement, but there are present the actors and representatives of the "political parties", leaders of private companies, state sectors, among other organizations each with own interests, but the great absentee are the Quechua, Aymara and Amazonian peoples, of which no means of communication informs, but rather undermine and legitimize the colonization process towards these peoples (Alanoca, Mamani, \& Condori, 2018). 
Existen trabajos individuales de profesionales de las distintas universidades, los cuales por el egocentrismo y centralismo solapado limeño y localista no son citados ni tomados en cuenta, están supeditados a las élites y la jerarquización social, con la mundialización de las comunicaciones, la cultura se transforma más y más en un recurso político. Y toda actividad social puede verse investida por una dimensión cultural (Wolton, 2003). Urge recrear acciones concretas desde los propios actores y sujetos y no objetos.

A medida que nuestro mundo político, económico, social y tecnológico va cambiando, las tácticas y estrategias que antes eran capaces de transformar el poder colectivo en ganancias emancipadoras han perdido su efectividad. En tanto sentido común de la izquierda actual, la política folk suele operar de manera intuitiva, poco crítica e inconsciente. Empero, el sentido común también es histórico y mutable (Williams \& Srnicek, 2017).

Una de las forma de recrear es la producción y creación de espacios donde se difunden y se expresan bajo sus propios actores mediante el uso de las tecnologías de información y comunicación y vía física e impresa, sin salirse de los marcos de sentido de pertinencia, en esa lógica pudimos apreciar hasta tres revistas muy interesantes como son: la Revista de Pensamiento Crítico Aymara, dirigido por Vicente Alanoca de la Asociación Centro de investigación y Escuela de Pensamiento Aymara (ACIEPCA); Revista Innova Educación del Instituto Universitario de Investigación, dirigido por Wilson Sucari Turpo del Instituto Universitario de Investigación Inudi Perú; y la Revista Revoluciones Estudios en Ciencia Política, Humanidades y Ciencias Sociales dirigido por el investigador Jesús Wiliam Huanca-Arohuanca; obviamente no son los únicos, pero sí son las que pretenden transitas o son las voces nuevas del pensamiento emancipatorio. Son las que van a combinar una forma actualizada de pensar la política (un desplazamiento de la inmediatez al análisis estructural) con un medio renovado de hacer política (que dirija la acción hacia la construcción de plataformas y la expansión de escalas) (Williams \& Srnicek, 2017).

Existen dos antecedentes muy interesantes que nos podría ayudar comprender las producciones y trabajos, como fue el Instituto de Estudios Aymaras (IDEA), fundada por la congregación de Maryknoll que tenía su sede en Chucuito, luego va ser desactivada o cerrada por la presencia y del Opus Dei, lo interesante y aporte de IDEA fue la producción de dos tipos de publicación muy interesantes, como los Boletines Ocasionales y el Boletín IDEA que eran secuenciales y tenían periodicidad dirigido por gente de mucha experiencia y trayectoria en etnografía y teología, como Diego Irrazabal, Domingo Llanque, entre otros, sobre todo sacerdotes, allí existen aportes de dos personajes un poco desconocidos y tal vez o mejor dicho no reconocidos como Victor Ochoa y Santiago Mendoza, fueron valiosísimas sus aportes, obviamente no son los únicos, pero tuvo muchos trabajos etnográficos.

A raíz de esa desactivación se funda lo que hoy es el Instituto de Estudios de las Culturas Andinas (IDECA), bajo la dirección de Simón Pedro Arnold, desde donde se habían creado algunas publicaciones como: Diálogos A, Testimonios de fe, Cuadernos de Observatorio, entre otras publicaciones, a pesar de actividades muy interesantes y coyunturales, por ejemplo se tenía la Maestría en Religiones y Culturas Andinas, en convenio con la Universidad 
Católica de Santa María (Arequipa), como que se estancó en la producción como fue en sus inicios. Por otro lado, vinculado a IDECA surge y se crea la Revista Pluralidades, aunque su lema reza: revista para el debate intercultural, está un poco desligado de la cotidianidad, se vuelve elitista y sellado para una célula "intelectual" tendrán sus razones, del cual somos respetuosos y que en la práctica son y siguen siendo voces de otros por los otros, no estamos cuestionando sus aportes que son interesantes e importantes, pero desligado de la realidad. Aunque algunos sostienen, que, es necesario que las ciencias sociales tienen que asegurarse de antemano de la adecuación de sus categorías al objeto, porque los esquemas de ordenación a que se ajustan (sólo contingentemente) magnitudes covariantes, yerran nuestro interés por la sociedad (Habermas , 2015). No se apuesta en la práctica por una real descolonización ni intercultural, aunque se escriba tomo y volúmenes referidos a ellos. Estos pueden convertirse en velos que pueden ocultar y silenciar esas voces silenciadas.

Hace falta tal vez hoy las dos publicaciones de lo que fue el Instituto de Pastoral Andina (IPA), con sus publicaciones como la revista Pastoral Andina y el Allpanchis igual fue frustrada silenciado por la iglesia del Opus Dei. No podemos olvidar los trabajos del Instituto de Investigación para el Desarrollo Social del Altiplano de los que era parte de la Universidad Nacional Técnica del Altiplano UNTA, hoy ya extinguido, no podemos negar los aportes de aquellos maestros que lucharon y crearon las dos primeras maestrías como de Desarrollo Rural y Lingüística Andina y Educación, que en el proceso fue perdiendo su incidencia en el debate y la reflexión crítica. En suma, de estos espacios han ido egresando algunos que comprendieron y abrazaron una voz y acción emancipatoria, que son inicios de una etapa compleja ya adversa.

No podemos seguir siendo colonias del conocimiento, toca hoy más que nunca quitarnos esos velos del colonialismo o la colonialidad del poder (Quijano, 2014), debido a que la gran mayoría de los trabajos sobre el conjunto de las ciencias sociales son descriptivos, con diversas metodologías y enfoques, con énfasis en autores y escuelas. Son muy poco los trabajos dedicados a una tematización o problematización de las mismas (Maldonado, 2016), del cual hay que salir, claro es innegable que todas las culturas desarrollan un lenguaje como respuesta a las exigencias del entorno (Herrera, 2005), no podemos callar o ser indiferentes como diría Gramsci.

En esa perspectiva surge y nace esta revista Revoluciones, probablemente atemoriza el nombre, claro es evidente, no sólo por su nombre, sino que es otra tribuna o plataforma para encarar y encarnar las otras voces nuevas de pensamiento emancipatorio. Creo que gira o debería girar en la descolonización, que se propone cambiar el orden del mundo, es, como se ve, un programa de desorden absoluto (Fanon, 2018), a pesar de que las palabras pueden ser engañosas (Monedero, 2009), ello implica y llama a la coherencia y acción emancipatoria por la dignidad humana.

\section{CONCLUSIONES}


A pesar del confinamiento no sólo por la pandemia de la Covid-19, sino que el proceso de silenciamiento de las otras voces fue sistemática en la historia de los pueblos aplastada, hoy bajo el nombre del virus, que estamos encerrados, más aún invisibilizados, amenazados y susceptibles de contagio, en ese contexto surgen otras voces como es la revista Revoluciones, que es una nueva voz y elemento de las líneas de pensamiento y acción emancipatoria. Revoluciones es una publicación que surge y nace desde esas voces silenciadas y relegadas, esfuerzo de un colectivo decido a acoger líneas y acciones de esperanza a pesar de la crisis. Obviamente, sin menospreciar otras producciones de antaño, o las que se vienen gestando o se han ido trabajando desde las universidades, pero hoy es una cosa incierta, no sólo por la situación de la pandemia, sino por la denegación de licenciamiento de dos universidades asentadas en Puno. Esta producción, dará mucho que hablar, debatir, sobre todo encarar y encarnar sobre la formas de hacer ciencia política, humanidades y sociales, como reza su título y el sub título, sabiendo que es complejo empezar, abrir los velos de la exclusión y entrar a la palestra del debate, donde persiste el racismo y el egocentrismo no sólo local, sino nacional, sin embargo, se circunscribirá desde sus contendidos en la perspectiva de la descolonización y en el marco de una interculturalidad emancipatoria, si así lo van a direccionar y lastrar sus directivos. Sabemos que la verdadera arma de la revolución en los tiempos actuales es la educación, esto reta ser revolucionario de verdad las formas de pensar, hacer, saber, actuar, querer y actuar por la dignidad humana desde esta parte del país. Sabiendo que las ciencias sociales están siendo asediadas.

\section{REFERENCIAS BIBLIOGRÁFICAS}

Alanoca, V. (2016). El desarrollo del pensamiento crítico en el altiplano de Puno. Comuni@cción,60-68.

Alanoca, V. (2017). La universidad en el proceso de la reconstrucción del pensamiento crítico. Revista de Investigaciones Altoandinas, 119-124. doi:Revista de Investigaciones Altoandinas

Alanoca, V. (2017). Los aymaras de Ilave (Perú). Su configuración como nuevos actores y sujetos históricos en la larga lucha de emancipación indígena. Sevilla: Universidad Pablo de Olavide.

Alanoca, V. (2019). La Necrademia y Ahayu Watan en el Quri Challwa de Gamaliel Churata, como ingredientes del pensamiento emancipatorio desde el Sur Andino. En D. y. Espezúa, Churata desde el Sur (págs. 205-220). Lima: Pakarina.

Alanoca, V., Condori, W., \& Mamani, O. (2019). El significado de la educación para la nación Aymara. Revista Historia de la Educación Latinoamericana, 227-246. doi:htps://doi.org/10.19053/01227238.6994

Alanoca, V., Mamani, O., \& Condori, W. (2018). Discrimination against the Aymaras in the Surandino (Puno) in the XXI century. International Journal of English Literature and Social Sciences (IJELS), 3(3), 318-326. doi:https://doi.org/10.22161/ijels.3.3.4

Alarco, G. (2019). ¿La dificil tarea de redistribuir ingresos en el Perú? En F. Portocarrero, \& A. Vergara, Aproximaciones al Perú de hoy desde las ciencias sociales (págs. 149-176). Lima: Universidad del Pacífico.

Anderson, B. (1997). Comunidades imaginadas. México: Fondo de Cultura Económica. 
Bonfil, G. (2001). México profundo. Una civilización negada. México: Conaculta.

Fanon, F. (2018). Los condenados de la tierra. México: Fondo de Cultura Económico.

Gramsci, A. (1967). La fromación de los intelectuales. México: Grijalbo.

Habermas, J. (2015). La lógica de las ciencias sociales. Madrid: Tecnos.

Herrera, J. (2005). Los derechos humanos como productos culturales. Pamplona: Catarata. Kymlicka, W. (1996). ciudadanía multicultural. Barcelona: Paidós.

Maldonado, C. (2016). Complejidad de las ciencias sociales. Y de otras ciencias y disciplinas. Bogotá: Desde abajo.

Martin-Barebero, J. (1987). De los medios a las mediaciones: comunicación, cultura y hegemonía, México, Gustavo Gilí, 1987. México: Gustavo Gilí.

Monedero, J. C. (2009). El gobierno de las palabras. Madrid: Fondo de Cultura Económica. Ortega y Gasset, J. (1975). La rebelión de las masas. Lima: Universo.

Pérez, R. (2020). Los asedios a las academias. En A. Basail, \& (Coord.), Academias asediadas (págs. 27-50). Buenos Aires: Consejo Latinoamericano de Ciencias Sociales.

Portocarrero, F., \& Vergara, A. (2019). Aproximaciones al Perú de hoy desde las ciencias sociales. Lima: Universidad del Pacífico.

Portocarrero, G. (2015). La urgencia por decir "nosotros". Lima: Pontificia Universidad Católica del Perú.

Quijano, A. (2014). Colonialidad del poder, eurocentrismo y América Latina. En Cuestiones y horizontes: de la dependencia histórico-estructural a la colonialidad/descolonialidad del poder (págs. 777-833). Buenos Aires: Consejo Latinoamericano de Ciencias Sociales (CLACSO).

Santos, B. (2010). Descolonizar el saber, reinventar el poder. Montevideo: Trilce.

Santos, B. (2020). La cruel pedagogía del virus. Buenos Aires: Consejo Latinoamericano de Ciencias Sociales.

Silleta, A. (2007). Shopping espiritual. Buenos Aires: Planeta.

UNESCO. (2016). Informe mundial sobre las ciencias sociales. Paris: Organización de las Naciones Unidas para la Educación, la Ciencia y la Cultura.

Williams, A., \& Srnicek, N. (2017). Inventar el futuro. Poscapitalismo y un mundo sin trabajo. Barcelona: Malpaso.

Wolton, D. (2003). La otra mundialización. Barcelona: Gedisa. 